\title{
El Poema de Mio Cid \\ y las colecciones de cuentos árabes y hebreos. Las arcas de los judíos Rachel y Vidas
}

\author{
José Ramírez del Río* \\ Universidad de Córdoba
}

ORCID ID: https://orcid.org/0000-0002-9329-5658

El episodio del engaño de las arcas en el Poema de Mio Cid (PMC) ha recibido diferentes interpretaciones. Proponemos analizar de forma detenida aspectos relacionados con la representación del $P M C$ cuya interpretación dependía de la reelaboración de narraciones cortas de origen árabe y hebreo, y que eran conocidas por el público al que iba dirigido el $P M C$. El motivo literario presente en las narraciones acerca de robos sufridos por judíos piadosos que eran resarcidos por Dios y que constituían una victoria sobre los paganos o los cristianos, va a ser invertido en esta ocasión para destacar la superioridad de la fe cristiana. La evolución del motivo literario propuesto en las diferentes tradiciones señaladas será también objeto de estudio.

Palabras Clave: Cuentos árabes; cuentos hebreos; motivo literario.

The Poema de Mio Cid and the Arabic and Hebrew Tales Collections. The Arks of the Jews Rachel and Vidas.- The Ark's episode in the Mio Cid's Song has been dealt with at length. Nonetheless, it is necessary to analyze the literary interplay, its reference to the Arabic and Hebrew tales which provide the background to understand the Ark's episode fully within the frame of the Poem. The tales about the theft suffered by pious Jews who were rewarded by God and which highlighted the victory of their faith over the Pagans or the Christians are used this time to show up the Christian's faith superiority. In this paper we intend to analyze the development of this Literary Motif in Mediaeval Literature.

Keywords: Arabic Tales; Hebrew Tales; Literary Motif.

*1r1rarij@uco.es

Copyright: (C) 2019 CSIC. Este es un artículo de acceso abierto distribuido bajo los términos de la licencia de uso y distribución Creative Commons Reconocimiento 4.0 Internacional (CC BY 4.0). 


\section{INTRODUCCIÓN}

El episodio de las arcas de arena con las que el Cid engaña a los judíos de Burgos, Rachel y Vidas, ha dado lugar a uno de los debates más prolongados de la crítica del Poema de Mio Cid (en adelante $P M C)^{1}$.

En líneas generales todos los críticos que han abordado este asunto aceptan el carácter ficticio, literario, de este texto, con la única excepción de E. García Gómez, que venía a considerarlo posible -incluso probable- y una muestra más de los engaños de los nómadas a los habitantes de las ciudades ${ }^{2}$. Consideramos que este aspecto quedó cerrado hace mucho tiempo, y no se puede atribuir historicidad alguna a esta narración.

Ramón Menéndez Pidal ${ }^{3}$ considera que el $P M C$ es ajeno al antisemitismo de otras obras medievales y atribuye la falta de pago a un mero olvido del juglar que dio forma final al $P M C$, pero que formaba parte del Cantar de Gormaz, la primera redacción del poema, que es la razón

${ }^{1}$ Gisele RoITman, «El episodio de Rachel y Vidas, polifónico y al mismo tiempo, velado», Revista de Literatura Medieval 23 (2011) págs. 237-259; Miguel GARCI-GóMEZ, El Burgos de Mio Cid. Temas socio-económicos y escolásticos, con revisión del antisemitismo (Burgos: Diputación Provincial de Burgos, 1982) págs. 141-142; Colin Sмітн, «Did the Cid repay the Jews?», Romania 86 (1965) págs. 520-538; Alfonso BoIx JovaNí, «El Cid pagó a los judíos», La Corónica 35:1 (2006) págs. 67-82: 67-68, y «La primera victoria del Cid en el Poema de Mío Cid», Revista de Literatura Medieval 26 (2014) págs. 363-368; Alberto Montaner, Cantar de Mio Cid. Edición, estudio y notas con un ensayo de Francisco Rico (Madrid: Real Academia Española-Galaxia Gutenberg, 2011) págs. 673-675 y 857-860.

2 En Emilio García Gómez, «Esos dos judíos de Burgos», Al-Andalus XVI:1 (1951) págs. 224-227: 227, leemos: «El Cid era, además, un caballero andante y errante, un gran nómada, y no es extraño que, en un apuro y a la fuerza, explotara, como sus colegas beduinos, a unos miserables sedentarios «de bárbaro linaje». La opinión de Francisco Cantera Burgos («Raquel e Vidas», Sefarad 18:1 [1958] págs. 99-108) era bien distinta, aunque se centraba en debatir principalmente la identificación de los dos personajes judíos, y su condición de matrimonio o de socios.

3 Ramón MenÉndez Pidal, En torno al poema del Cid (Madrid: Edhasa, 1963) págs. 207-208. 
por la que en textos muy posteriores ${ }^{4}$ sí se produce el pago e incluso una petición de disculpa del Cid a través de su enviado a los prestamistas. Dado que ni siquiera la existencia de esas dos fases en la creación del poema ha sido seguida por buena parte de la crítica contemporánea, parece necesario buscar una explicación diferente.

Colin Smith rechazó en su día que el Cid hubiera pagado esa deuda, aunque apenas presta atención al propio carácter judío de los prestamistas $^{5}$ : la falta de pago se debía a la condición de personaje situado por encima de las convenciones sociales de su tiempo a partir del momento en que es desterrado ${ }^{6}$.

Alfonso Boix ha hecho un esfuerzo para integrar este texto en el conjunto del $P M C$, indicando que el engaño a los judíos es la primera victoria del Cid y apartándose un poco del aspecto moral del asunto, que posiblemente sea, junto con el posible antisemitismo del Cid, los aspectos que más atención han suscitado hasta la fecha en los estudios relativos al episodio de las arcas en el PMC. Boix considera que el Cid, finalmente, pagó su deuda con los prestamistas judíos. Sus estudios, de gran mérito, abundan en aspectos pocos estudiados del PMC hasta la fecha, aunque sus conclusiones en este asunto en particular son diferentes de las que presentamos en estas páginas. Boix también mostró la

${ }^{4}$ Primera Crónica General, ed. Ramón Menéndez Pidal (Madrid: Gredos, 1955) pág. 593; Crónica del famoso Cavallero Cid Ruy Diez Campeador, apud José M. ${ }^{\text {a VIÑA }}$ Liste, (ed.), Mio Cid Campeador (Madrid: Biblioteca Castro, 2006) cap. 213. Algunos romances, creados sobre las versiones de prosa de las crónicas medievales, también hacen que el Cid pague esta deuda; $c f$. Ramón Menéndez Pidal, Flor nueva de romances viejos (Madrid: Austral, 2006) pág. 171.

5 Aunque curiosamente Donald McGrady («Did the Cid Repay the Jews? A Reconsideration», Romania 106 [1985] págs. 518-527: 522) expresando una corriente que aparece con Andrés Bello, daba por hecho que era precisamente su carácter judío el que producía el impago del Cid: «It therefore becomes apparent that the Cid does not repay his debt because his creditors are Jewish».

${ }^{6}$ Colin Sмiтн («Did the Cid repay the Jews?», págs. 537-538) se muestra en sus conclusiones incluso mordaz con la posibilidad de que hubiera pagado: «That Cid did not repay all his debts like a good petit bourgeois concerned to safeguard society and to obey its rules. Those that made him do so in the later Middle Ages, and even - be it said with the very greatest deference - those that make him do so today, seem to me to diminish his epic stature in the interests of a respectability which has no attraction. We are all more or less respectable; epic heroes are few». 
importancia de los cuentos tradicionales integrados en la estructura del $P M C$, con los que el autor consigue crear una estructura funcional desde un punto de vista literario ${ }^{7}$. En este aspecto, concretamente en lo relativo al episodio de las arcas, sus estudios parecen seguir los emprendidos por Nicasio Salvador Miguel $^{8}$, que estudió este asunto en el marco de los diccionarios de motivo folclóricos ${ }^{9}$, y en el que esperamos quede inscrito el presente trabajo.

El antijudaísmo de buena parte de los textos medievales hispanos nos había conducido hasta la fecha a buscar en la literatura andalusí el origen de este episodio, en especial en la siguiente narración:

Sa 'dūn b. Fath al-Surunbāqī... lo apresaron los maŷūs que llegaron a la costa occidental de al-Andalus en tiempos del emir Muhammad, y lo rescató un mercader judío que buscaba conseguir ganancias; (Sa 'dūn) prometió al judío recompensarle hasta que consiguió huir de él, pero luego defraudó su confianza y le hizo perder su dinero ${ }^{10}$.

7 Alfonso Borx Jovaní, «El Cantar de Mio Cid y la inversión de los modelos narrativos folclóricos», Hispanic Research Journal 8:2 (2007) págs. 99-105: 104: «El presente estudio muestra cómo, ... existe una estructura narrativa que coincide con la de los cuentos populares. ... se observa cómo todos estos elementos forman parte de una estructura mayor, la del cuento folclórico...».

8 Nicasio Salvador Miguel, «Reflexiones sobre el episodio de Rachel y Vidas en el Cantar de Mio Cid», Revista de Filología Española 59:1 (1977) págs. 183-224. Este trabajo fue completado en algunos aspectos de detalle en el capítulo de libro del mismo autor «Unas glosas más al episodio de Rachel y Vidas en el Cantar de Mio Cid», en Serta Philologica F. Lázaro Carreter, II. Estudios de literatura y crítica textual (Madrid: Cátedra, 1983) págs. 493-498.

${ }^{9}$ El propio autor indicó que este acercamiento ya lo habían emprendido Alan D. Deyermond y Margaret Chaplin («Folk-Motifs in the Medieval Spanish Epic», Philological Quarterly 51 [1972] págs. 36-53: 41), quienes señalaban que el motivo es el recogido en los números K. 455.9 y 476.2.2 de la obra de Stith Thompson, Motif-lndex of Folk-Literature. A Classification of Narrative Elements in Folktales, Ballads, Myths, Fables, Mediaeval Romances, Exempla, Fabliaux, Jest-Books, and Local Legends (Bloomington: Indiana University Press, 1955-1958). Sin embargo, Nicasio Salvador Miguel le dio una amplitud y profundidad a su estudio que nada tenía que ver con las breves notas de sus ilustres predecesores.

${ }^{10}$ IBN HayYȳn, Kitāb al-muqtabis fì ta'rij riŷāl al-Andalus, vol. III, ed. Melchor Martínez Antuña (Paris: Librairie Orientaliste Paul Geuthner, 1937) pág. 23. Ya 1lamamos la atención sobre este hecho en Jośe Ramírez Del Río, «Notas acerca de un texto épico en al-Andalus», Anaquel de Estudios Árabes 14 (2001) págs. 219-230. 
Se trata de un texto muy peculiar dentro de la producción cronística de Ibn Hayyān, que solía utilizar información cronística, procedente de la obra perdida de al-Rāzīi ${ }^{11}$, en un buen número de casos, de la documentación oficial a la que tuvo acceso gracias a su posición en la administración de Córdoba, la capital de al-Andalus, y en ocasiones, como es el caso, a las composiciones de poetas locales en las que ensalzaban a los personajes que habían pagado por ellas, como sucedió en este texto con el arraez rebelde de Badajoz 'Abd al-Raḥmān al-Ŷilliqīi ${ }^{12}$, que en ocasiones actuaba bajo la autoridad omeya y en otras se rebelaba contra ella. La alusión a Sa dūn b. Fath al-Surunbāqī procede de la obra dedicada a al-Ŷilliqī, en la que los elementos literarios, usados para ennoblecer la figura de 'Abd al-Raḥmān al-Ŷilliqī, eran muy frecuentes y en muchos casos procedían de los ayyām al- $a r a b^{13}$.

\section{El MOtivo Literario DEL ENGAÑo DE LAS ARCAS}

Sin dejar de lado este motivo literario de origen árabe que hemos señalado, que posiblemente explique la popularidad del engaño a los judíos para robarles dinero como elemento muy arraigado en toda la Europa medieval, debemos prestar más atención a las propias arcas que sirven de instrumento en el caso del $P M C$ a la estafa, ya que este elemento material había formado parte de una tradición literaria de importancia capital en el desarrollo de las letras hispanas: la cuentística de origen árabe, en este caso llegada gracias a los autores y traductores judeo-árabes. Resulta llamativa la importancia que los castellanos atribuyeron al propio elemento material de las arcas; en el monasterio de Cardeña se exhibía una de las usadas en el engaño a los judíos dentro

11 Luis Molina, «Sobre la Historia de al-Razi. Nuevos datos en el Muqtabis de Ibn Hayyān», Al-Qanțara 1 (1980) págs. 435-441.

12 Vid. Fernando VALDÉs, «La mezquita privada de Abd al-Rahman b. Marwan alYilliqi en la alcazaba de Badajoz», CUPAUAM 25:2 (1999) págs. 267-290; María Jesús Viguera Molins, «La ciudad de Badajoz en la antología lírica del Mugrib de Ibn Sa‘id», en Mil años de libros, coord. Fernando Díaz Esteban (Badajoz: Biblioteca de Extremadura, 2014) págs. 225-238.

13 Jośe Ramírez Del Río, La Orientalización de al-Andalus. Los días de los árabes en la península Ibérica (Sevilla: Universidad, 2002). 
del pequeño museo que los monjes crearon alrededor de la figura del $\mathrm{Cid}^{14}$.

Aunque la denominada "crítica hidráulica" 15 reciba en diferentes casos críticas, que pueden ser bien fundadas sobre todo en el caso de la literatura contemporánea, en el caso de la literatura medieval el uso y reaprovechamiento de motivos literarios anteriores es continuo, y no tenerlo en cuenta resultaría un error metodológico evidente.

La primera obra que traeremos a colación es de Nissim ben Ya qūb ibn Šahīn ${ }^{16}$, un escritor judío tunecino del siglo XI que compuso una colección de relatos edificantes, con el propósito declarado de animar a una persona cercana por la pérdida de un ser querido. Mientras en la obra de al-Tanūjīi ${ }^{17}$ que dio popularidad al género narrativo de al-Faray ba 'd al-šidda [=El alivio tras la prueba, La alegría tras la angustia,] la prueba solía ser un grave aprieto debido a la enemistad de un personaje poderoso, y el personaje afectado pedía ayuda a Dios, que le ayudaba a superar a su rival terrenal, en el caso de las colecciones en judeo-árabe esa angustia es en muchas ocasiones debida a un problema religioso, que es superado gracias a la ayuda de Dios; en muchas ocasiones incluyen

14 Irene ZaDERENKo, «The Question of Autorship», en A Companion to the "Poema de Mio Cid", eds. Irene ZADEREnKo y Alberto MontAnER (Leiden: Brill, 2018) págs. 89116: 108 .

15 Expresión de Pedro Salinas, que venía a resumir toda una corriente crítica negativa hacia el estudio de fuentes; $c f$. José Francisco RuIz CASANOVA, «La melancolía del orangután. El origen de los estudios A en B. Menéndez Pelayo y su Horacio en España», en Traducción y traductores: del Romanticismo al Realismo, eds. Francisco LAFARGa y Luis Pegenaute (Bern: Peter Lang, 2006) págs. 407-417.

16 Nissim Ben YA 'QūB IBN ŠAhĪN, Al-Faraŷ ba'd al-šidda, ed. Julian OBermanN (New Haven: Yale University Press, 1933), accesible en https://babel.hathitrust.org/cgi/ pt?id=mdp.39015034106057;view=1up;seq=1 [rescatado el 25/01/2017]; tr. al inglés William M. BRINNER, An Elegant Composition concerning Relief after Adversity (New Haven: Yale University Press, 1977).

17 Al-Tanūīi, Al-Farâ̂ ba'd al-šidda (Beirut: Dār Sāqī, 2010), y La délivrance apres l'épreuve (Paris: Actes du Sud, 2006); vid. Julia BrAY, «Practical Mu tazilism: The Case of al-Tanūkhī»', en 'Abbasid Studies. Occasional Papers of the School of 'Abbasid Studies Cambridge 6-10 July 2002, ed. James E. Montgomery (Leuven: Peeters, 2004) págs. 111-126, y «The Physical World and the Writer's Eye: Al-Tanūkhī and Medicine», en Writing and Representation in Medieval Islam. Muslim Horizons, ed. Julia BrAY (London: Routledge, 2006) págs. 215-249. 
fragmentos procedentes de las obras árabes. El tono en líneas generales es mucho más ligero en los textos de al-Tanūjī que en los de sus epígonos judíos, pues los elementos humorísticos, las burlas y los chistes tienen un lugar en sus obras que difícilmente encontramos en los continuadores del género.

El género al-Faraŷ ba'd al-šidda no es en modo alguno único en la prosa árabe de carácter moralizante o didáctica: otros títulos cercanos convertidos en rúbricas de subgéneros como Makārim al-ajlāq $[=$ Nobleza de costumbres] venían dando una impronta fuertemente religiosa, con una ética teísta en la que la intervención de la divinidad para sancionar comportamientos incorrectos y recompensar a los piadosos era la norma. Los cuentos generados en estas obras, desde la época de Ibn Abī al-Dunyā ${ }^{18}$, casi un siglo anterior a al-Tanūjīi, fueron incorporados posteriormente a las colecciones de cuentos que circularon por todo el mundo árabo-islámico durante los siglos siguientes. Resulta difícil trazar un marco fiable del desarrollo de este género, pues se han perdido muchas de las principales colecciones, desde la del propio fundador del género, Abū l-Ḥasan al-Madā'inī (m. 830), de la que sólo se conservan algunos folios, hasta muchos de los pasos intermedios hasta el propio al- Tanūjī. ¿Fue Ibn Abī al-Dunyā el primero que introdujo hadices en estas narraciones, dándole un carácter mucho más edificante? La evolución de este género, del que hemos perdido documentos capitales, resulta más intrigante cuando en el caso de un mismo autor encontramos formas de narrar cambiantes, como ha demostrado Schippers ${ }^{19}$.

Sin embargo, la importancia concedida a algunas colecciones como Las Mil y una noches o Calila wa-dimma, con bibliografías extensísimas ${ }^{20}$, ha oscurecido otras colecciones que en época medieval llegaron a adquirir un renombre mayor.

18 James A. Bellamy, «The Makārim al-Akhlāq by Ibn Abi -1-Dunyā», The Muslim World 53 (1963) págs. 106-119, e IBN AB̄̄ AL-DunYĀ, Kitāb Makārim al-Ajlāq, ed. James A. Bellamy (Wiesbaden: Franz Steiner Verlag, 1973).

19 Arie SCHIPPERS, «Changing narrativity in a changing society. The dichotomy between the "early" and the "later" stories in Tanukhi's Relief after Adversity», Quaderni di Studi Arabi 20-21 (2002-2003) págs. 39-51.

20 Mil y una noches, trad. Salvador PEÑa (2. ${ }^{\text {a }}$ ed., Madrid: Verbum, 2018) es la última traducción al español, ganadora del Premio Nacional de Traducción 2018. Desde el punto 
El puente entre las literatura árabe, en especial la cuentística, y la literatura castellana hemos de buscarlo principalmente en al-Andalus y en los géneros narrativos que se desarrollaron entre los siglos IX y XII. Sin embargo, la historia de dichos géneros aún debe ser escrita, en parte por la pobre opinión que los propio andalusíes tenían de las personas que se dedicaban a los mismos, los qușṣās, de los que incluso nos cuentan las fuentes que debían ser estrechamente vigilados por las autoridades para no descarriar con sus invenciones a los musulmanes ${ }^{21}$. En parte se trata también de una carencia de la crítica literaria en el campo de estudios andalusí, que no ha producido hasta la fecha una obra o un conjunto de trabajos que permita conocer de forma adecuada la prosa narrativa escrita en al-Andalus ${ }^{22}$.

La prosa medieval castellana bebió de las obras de origen oriental y sus traducciones fueron uno de los aspectos más decisivos en la evolución de la prosa castellana ${ }^{23}$. Dentro de estas obras es sobradamente conocida la relevancia que tuvo la colección de cuentos de Pedro Alfonso, judío converso de Huesca del s. XII, Disciplina Clericalis ${ }^{24}$. E1 estudio de las fuentes ha sido más amplio que en otras colecciones, destacando obras de origen griego como las fábulas de Esopo (exemplo V), Barlaam y Josafat, de origen polémico, posiblemente se trate de una adaptación cristiana, armenia traducida al griego, de la historia de Buda $^{25}$, el Calila wa-dimma y el Sendebar ${ }^{26}$ y obras de literatura sa-

de vista crítico podemos destacar en los últimos años la obra de ABD AL-FATAH KiLITO, Les arabes et l'art du récit: une étrange familiarité (Paris: Sindbad-Actes Sud, 2009).

21 Eduardo Manzano, La corte del califa (Barcelona: Crítica, 2019) pág. 311.

22 Los trabajos de Fernando DE LA GRANJA como su Maqamas y risalas andaluzas (Madrid: Hiperión, 1997), van siendo seguidos con cierta parsimonia por trabajos de Velázquez Basanta, Del Moral, García Arévalo....

23 Vid. Fernando Gómez Redondo, Historia de la prosa castellana medieval (Madrid: Cátedra, 1998), y Álvaro GALMÉs DE FuENTES, Influencias sintácticas y estilísticas del árabe en la prosa medieval castellana (Madrid: Gredos, 1996).

24 Vid. Ángel González Palencia, (ed.), Disciplina clericalis (Madrid-Granada: Consejo Superior de Investigaciones Científicas, 1948), y Esperanza DuCAY y M. a Jesús LACARra, (eds.), Disciplina clericalis (Zaragoza: Guara, 1980).

25 M. Jesús Lacarra, (ed.), Cuento y novela corta en España, 1. Edad Media (Barcelona: Crítica, 1999) págs. 108-110.

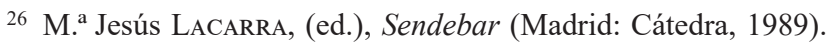


piencial, que transmitían sentencias de filósofos de la Antigüedad, como Plutarco, pasadas por el tamiz de la traducción al árabe. Sin embargo, resulta menos conocido en el campo de la romanística la relación entre Pedro Alfonso y las colecciones de cuentos de Yūsuf b. Zubāra y de Nissim ben Ya qūb ibn Šahīn ${ }^{27}$. Estas obras pertenecen al género narrativo indicado anteriormente. El siguiente texto de Ibn Šahīn resulta muy esclarecedor ${ }^{28}$ :

Por qué era llamado el hombre de Gamzu

Debes saber que la razón por la que era llamado Nahum, el hombre de Gam zu le-țobah ${ }^{29}$, porque cada vez que sufría una desgracia, decía: “¡Esto también será para bien!”, y no se quejaba ni se enfurecía. Una vez, los sabios de Israel, querían enviar un regalo al emperador [romano], y dijeron: "No tenemos a nadie como Nahum, el hombre de Gamzu. Enviémosle un presente con él, pues Dios, ensalzado sea, realiza muchos milagros y prodigios a través suyo". Entonces lo enviaron con unas arcas llenas de costosos vestidos, él las cogió y partió con ellas. Cuando llegaba a un lugar para pasar la noche, se las ponía junto a su cabecera y dormía así. Durante la noche, la gente de aquella ciudad se levantó y se llevaron todo lo que había en las arcas, llenándolas en su lugar de tierra. Al amanecer, él cogió las arcas y partió de nuevo; cuando se encontró frente a emperador, puso las arcas frente a él. El emperador ordenó abrirlas y se encontraron que estaban llenas de tierra. Sus visires dijeron al emperador: “ ¡Los judíos están haciendo burla de ti y de tu dignidad real!". Por consiguiente, el emperador ordenó ejecutar a Nahum, el hombre de Gamzu, que cuando era conducido para ser ejecutado dijo otra vez: “¡Esto también será para bien!”. En ese momento, el profeta Elías se apareció al emperador bajo la forma de uno de sus chambelanes

27 Arie SCHIPPERS, «Stories about Women in the collections of Nissim ibn Shāhīn, Petrus Alphonsi, and Yosef ibn Zabāra, and their relation to medieval European Narratives», Frankfurter Judaistische Beiträge 37 (2012) págs. 123-135.

28 NisSim BEN YA 'QūB IBN ŠAHĪn, Al-Faraŷ ba'd al-šidda, ed. OBERMAnN, págs. 2123; tr. al inglés: Brinner, An Elegant Composition concerning Relief after Adversity, págs. 26-27. Hay también traducción al español, localizada en Amparo Alba CeciLiA, Las primeras colecciones de cuentos hebreos medievales. Traducción y estudio (Madrid: Universidad Complutense, 1988) vol. II, págs. 675-677. En esta obra, resultado de su tesis doctoral, la autora tradujo el texto de los Exempla de los rabinos, datado entre los siglos XIII y XIV, y con un texto prácticamente idéntico.

${ }^{29}$ Que significa, en hebreo, ‘¡Esto también será para bien!'. En el texto original es una de las pocas cosas escritas en hebreo, casi todo lo demás está en árabe. 
y le dijo: “¡Oh rey! ¡Quizá esta tierra sea parte de la utilizada por Abraham, el amigo ${ }^{30}$, que cuando es arrojada contra el enemigo, se convierte en flechas y espadas contra él ¡Con ella capturaban ciudades asediadas!”.

Había una ciudad cercana que habían asediado desde hacía un tiempo considerable, sin resultado. Entonces arrojaron un poco de aquella tierra, que se convirtió en espadas y flechas y que les permitió conquistar la ciudad a continuación, por lo que el emperador, emocionado, ordenó que llenaran de nuevo las arcas con joyas preciosas, y que entregaran a Nahum, el hombre de Gamzu, un vestido de honor.

En su regreso de aquel viaje, Nahum pasó la noche en la misma ciudad en que pasó la noche cuando iba a ver al emperador. Cuando la gente vio que volvía entre honores y a salvo, le preguntaron: “¿Qué llevaste al emperador que fuera tan digno de recompensa?", y él replicó: "Fueron las arcas que llevé, cuando las abrieron las encontraron llenas de arena, y me recompensaron por ello". Tras escuchar aquello, la gente de aquella ciudad cogió también unas arcas, las llenaron de arena y la llevaron ante el emperador, diciendo: “¡Oh rey! ¡Esta es arena igual que la que los judíos te enviaron!". El emperador ordenó que la probaran, y al comprobar que no pasaba nada, el emperador ordenó que fueran ejecutados, y todos fueron muertos, hasta el último.

El intento de engañar a Nahum de Gamzu por parte de los gentiles se ve rebatido por la intervención del Profeta Elías, por lo que la trama narrativa se presenta como un triunfo de la verdadera religión, la del judío. Esta narración, incluida en una obra de Al-Faraŷ ba'd al-šidda, en una colección de cuentos de carácter edificante que circuló tanto en árabe como en hebreo, tiene fuentes en la literatura hebrea, en el Talmud de Babilonia ${ }^{31}$.

Como podemos observar en el texto, no es el ofensor en primera instancia el que resulta castigado, aunque desde luego sí termine reca-

30 Al-Jalīl 'el amigo de Dios', epíteto frecuente para referirse a Abraham tanto en la literatura árabe -ya que así es citado en Corán, 4:125-, como en la hebrea y en la tradición cristiana, en cuyos libros sagrados figura con ese título: $c f$. Haim Zeev HirschBERG, Hibbur Yafeh mehay Yeshu'ah (Jerusalem, 1953) pág. 14, nota 3; Sagrada Biblia (Madrid: BAC, 2016) Isaías 41:8.

31 Babylonian Talmud (London, 1955) Ta anit, 21a; Richard Lee Kalmin, Migrating Tales: the Talmud's Narratives and Their Historical Context (Oakland: California University Press, 2014). 
yendo sobre él su pecado, por su avaricia, siendo ejecutados los hombres de la ciudad por el emperador.

En modo alguno se trata de la única leyenda en la que los cofres y la devolución de préstamos tienen gran importancia en la tradición judía. Akiba $b$. Joseph es una de las figuras más distinguidas de la historia del judaísmo, hasta el punto de que en ocasiones es comparado favorablemente con el propio Moisés ${ }^{32}$. En un comentario del Talmud aparece esta narración, de evidente color popular, que explica una de las seis formas en que Rabbi Akiba hizo fortuna:

Akiba y la Matrona.

El éxito de Akiba como maestro terminó con su pobreza, pues su acaudalado suegro se complació entonces en reconocer a un yerno tan distinguido como Akiba. Sin embargo, fueron otras las circunstancias que hicieron de él un hombre rico tras ser anteriormente un simple pastor. Al parecer, Akiba, tras recibir la autorización de varios rabbis, tomó prestada una gran cantidad de dinero de una prominente mujer gentil - una matrona, dice la leyenda-, para construir su escuela. Como garantes de su acuerdo Akiba designó a Dios y al mar, a la orilla del lugar en que se encontraba la residencia de aquella mujer. Estando Akiba enfermo, no pudo devolver el dinero en el momento acordado, pero sus garantes lo hicieron: Una princesa imperial se volvió loca de manera repentina, y arrojó un cofre con tesoros reales al mar, que fue encontrado en la costa, junto a la residencia de la mujer, y cuando ésta fue a demandar al mar la cantidad que le había prestado a Akiba, la subida de la marea dejó a sus pies el cofre con incontables riquezas. Cuando Akiba llegó para saldar su deuda, la matrona no sólo rechazó el dinero, sino que insistió en que Akiba recibiera una gran parte de lo que el mar le había llevado a ella ${ }^{33}$.

Obviamente la semejanza con el episodio de las arcas del PMC es muy leve, por ejemplo no hay engaño alguno en este caso, al contrario de lo sucedido con el hombre de Gamzu; lo traemos a colación para

\footnotetext{
32 Babylonian Talmud-Menahot, $29 \mathrm{~b}$.

33 Babylonian Talmud-Nedarim, 50a-b. Traducido del inglés a partir de la versión disponible en http://www.jewishencyclopedia.com/articles/1033-akiba-ben-joseph [recuperado el 08/01/2017]; Shelomoh SKuLSKI, Legends of Rabbi Akiva (New York: Shulsinger Bros., 1975).
} 
mostrar hasta qué punto se va a ir generando en cuentos medievales hebreos la relación entre las arcas y la intervención divina para salvar de un apuro a una persona pía de religión hebrea.

Curiosamente una de las figuras más destacadas en la creación de la imagen legendaria de Akiba en la Edad Media fue Rabbenu Nissim de Gerona $^{34}$, aunque por otras referencias en la obra parece probable que se tratara del resultado de una obra anterior. Parece evidente que la asociación de Rabbi Akiba con el ciclo narrativo de Nahum de Gamzu ${ }^{35}$ resultó de trascendental importancia para la atribución a Akiba de este tipo de narraciones, que como hemos señalado, se produjo en un momento relativamente tardío (siglo XIV).

Estas dos historias de Rabbi Akiba y de Nahum de Gamzu son parte de un grupo más amplio de narraciones en que un personaje de religión hebrea necesita de manera imperiosa una cantidad de dinero, y esta es proporcionada por Dios, que demuestra así su favor por estos personajes piadosos. También hay narraciones en que el personaje pío consigue su propósito gracias a su astucia:

Capítulo XXIII.

La historia de Kidor

Algo parecido a la historia mencionada anteriormente le sucedió a algunos sabios ${ }^{36}$, en concreto a Rabbi Meir, Rabbi Judah y Rabbi José. Dejaron la tierra de Šām en un viaje, entraron en una ciudad el viernes por la tarde y pidieron hospitalidad a uno de sus habitantes. Cuando le

${ }^{34}$ En Barry W. Holtz, Rabbi Akiva, Sage of the Talmud (London: Yale University Press, 2017) pág. 80, leemos: «Aside from these two references, the Talmud gives no further details about this surprising episode of Akiva's marriage to Turnus Rufus's wife, but hundreds of years later the fourteenth century commentator Rabbenu Nissim of Gerona in his commentary on Tractate Nedarim filled in the details of the story from his own imagination».

35 Ben Zion Rosenfeld, Torah Centers and Rabbinic Activity in Palestine, 70-400 CE: History and Geographic Distribution, trad. Chava CASSEL (Leiden: Brill, 2010) págs. 61-62. De hecho, señala que Akiba fue discípulo de Nahum por veintidós años; vid. Ronald L. Eisenberg, Essential Figures in the Talmud (Plymouth: Jason Aronson, 2013) págs. 178-179.

36 Palabra escrita en hebreo, pero intercambiable con la versión árabe, incluso el artículo está escrito en árabe: al-hakamīn. 
preguntaron por su nombre, él respondió: "Mi nombre es Kidor ${ }^{37}$. Rabbi Judah y Rabbi José dejaron sus bolsas ${ }^{38}$ en depósito a Kidor, mientras Rabbi Meir no le dejó en depósito nada, sino que en lugar de ello fue al cementerio y enterró allí su monedero. Pasaron el Sabbath con Kidor, y cuando llegó el domingo, desearon reanudar su viaje y Rabbi Judah y Rabbi José le pidieron sus bolsos, pero Kidor les respondió: no me habéis dado nada". Le imploraron e incluso le ofrecieron parte del dinero, pero él no les admitió nada y no pudieron hacer que se arrepintiera. Angustiados y afligidos, preguntaron a Rabbi Meir: “¿Por qué no le entregasteis en depósito vuestro monedero a este hombre?" y él replicó: "Cuando le pregunté su nombre, él me respondió: 'Kidor' y yo recordé: Porque son una generación pervertida (Ki dor), unos hijos desleales" ${ }^{39}$; entonces sentí miedo y no me fie de él. Los dos sabios le dijeron: “¡Si nos lo hubieras dicho, habríamos estado en guardia contra él!". Él les respondió: "¿Cómo iba a advertiros de algo de lo que no estaba seguro y que se me ocurrió solo como algo dudoso?". Siguieron adelante y alquilaron una casa en la ciudad, e invitaron a Kidor a ser su huésped, con la esperanza de convencerlo para que devolviera parte de su dinero. Llegó allí poco antes de anochecer, y habiendo tomado lentejas antes y no habiéndose lavado las manos, quedaban restos de lenteja en sus manos. Cuando vieron eso, uno de ellos se levantó y fue a casa de Kidor, y le dijo a su mujer: "Tu esposo manda decirte: Con la clave de lo que he comido hoy por la tarde, que son lentejas, entrégale los bolsos que me dieron la víspera del Sabbath"; ella se los dio y él, regocijado, se lo contó a sus compañeros cuando hubo vuelto, pero no a Kidor. Por la mañana, ellos siguieron camino y Kidor volvió a su casa y preguntó a su mujer por sus monederos. Ella respondió: "Un hombre vino y se las llevó, siguiendo esta seña que enviaste con él”. Entonces él sacó la espada de su funda y le cortó la cabeza ${ }^{40}$.

Como es evidente, en este caso la astucia de los interesados es la que les permite salir victoriosos del trance, en otra variante dentro de las narraciones de arcas de dinero que estamos desarrollando, de manera breve, en estas líneas.

37 Nombre escrito en hebreo.

38 Akyas, أكياس

39 Deut 32:20.

$40 C f$. Nissim Ben YA 'QūB IBN Š́AHĪN, Al-Faraŷ ba'd al-šidda, págs. 110-111 (texto árabe) y 108-109 (versión inglesa). 
En la obra de Pedro Alfonso, Disciplina Clericalis, se produce una narración similar, en que un peregrino a La Meca recupera su dinero gracias a la intervención de una religiosa cristiana:

Ejemplo XV: los diez cofres

Me dijeron que un español fue a la Meca y, en su viaje, llegó a Egipto. Como iba a entrar en tierra desierta y a pasar por ella, pensó dejar en Egipto su dinero. Y antes de decidirse a dejarlo, preguntó si había allí un hombre honrado al que pudiera confiar su peculio. Le indicaron a uno viejo y conocido por su probidad, al que entregó mil talentos. Prosiguió luego su viaje y, de regreso, se presentó en casa de aquel a quien había dejado su dinero y le pidió que se lo devolviera. Pero él, lleno de malicia, decía que no lo había visto nunca. Viéndose así engañado, buscó ayuda en algunos hombres buenos de la vecindad de aquel, contándoles cómo se había portado con él el hombre al que confiara su dinero. Mas sus vecinos, aún oyéndole contar tales cosas, no quisieron creerlas, y antes de bien decían que no podía ser cierto. Y el cuitado que había perdido su dinero iba todos los días a casa del hombre que lo retenía injustamente y con buenas maneras le rogaba que se lo devolviera. Oyendo esto, el estafador le increpaba diciendo que no volviera a presentarse en su casa ni a hablarle de tal cosa, porque si lo hacía sería castigado. Y así, oídas las amenazas del hombre que le había engañado, tornábase muy triste de la casa. De regreso, se encontró un día a una mujer vestida con ropas de ermitaña. Sostenía sus frágiles miembros con un bastón y, alabando a Dios, por la calle iba quitando las piedras del camino de modo que no dañaran los pies de los caminantes. La cual viendo a un hombre llorando y conociendo que era extranjero, movida a piedad, lo llamó a un lugar apartado y le preguntó qué le acaecía. Él le contó todo tal como había sucedido. La mujer, al oír sus palabras, dijo: "Amigo, si es verdad lo que me contaste, he de ayudarte”. Y él: “¿Cómo puedes hacerlo, sierva de Dios?". Ella le dijo: "Tráeme un hombre de tu tierra en cuyas palabras y hechos puedas fiar". Y él lo trajo. Finalmente, mandó la mujer que el amigo de aquel que aquel que había sido estafado en sus dineros comprara diez cofres pintados por fuera con colores preciosos y que cerrados, con buenas cerraduras con hierro plateado y que, trayéndolos a casa de su huésped, los llenara de piedras menudas. Él lo hizo así. Y la mujer, cuando vio que todo estaba preparado como ella había mandado, volvió a decirle: "Busca diez hombres que, yendo conmigo y con tu socio a casa del que te engañó, se presenten ante él, llevando un cofre cada uno, y cuando el primero de la fila llegue ante la casa de ese hombre, preséntate tú y reclama tu dinero ¡que yo confío en 
Dios que te será devuelto!". Hizo él todo como le recomendara la anciana quien, no olvidada de su empeño, se puso también en camino. Y se presentó con el compañero de aquel que había sido víctima del fraude en casa del estafador, y dijo: "Un hombre de España estuvo hospedado en mi casa y ahora quiere ir a La Meca, pero antes desea encomendar a alguien la fortuna que está en esos diez cofres para que se la guarde. Así pues, yo te ruego que, por mí, aceptes guardarla en tu casa. Puesto que tengo oído y yo misma sé que eres un hombre bueno y honrado, no quiero que ninguno otro que tú se haga cargo [de la custodia] de este dinero". Y mientras ella hablaba así, apareció el primero de los que llevaban los cofres, a la vez que, a lo lejos, se veía la fila de los otros. Entre tanto, el que se había visto defraudado, no olvidando las recomendaciones de la viejecilla, se presentó, como ella le había dicho, detrás del primer cofre. Y el que le había guardado el dinero viéndolo venir, temiendo que, si volvía a reclamarlo, el otro no le confiara el suyo, lleno de maldad y de picardía le salió al encuentro diciendo: "Amigo mío, ¿dónde has estado tanto tiempo? ¡Ven y toma el dinero que me diste a guardar, pues que al fin te encontré y ya me cansa custodiarlo!'. Y así él, alegre y gozoso, recuperó su dinero. Mas la vieja, cuando vio que el hombre tenía su fortuna, se puso en marcha diciendo: "Iremos mi socio y yo al encuentro de nuestros cofres y diremos que los traigan aprisa. Espera tú hasta que volvamos y guarda bien el que ya te trajimos”. Él, muy contento, guardó el que ya había recibido y se quedó esperando la llegada de los otros; y puede que aún esté aguardando. Y así, por las artes de la viejecilla, recuperó aquel hombre su dinero ${ }^{41}$.

El motivo del depositario infiel ha sido destacado como un posible precedente del episodio del PMC tanto por Ramón Menéndez Pidal ${ }^{42}$ como por María Jesús Lacarra en la introducción de la Disciplina Clericalis $^{43}$.

41 Apud Pedro alfonso, Disciplina clericalis, eds. Ducay y Lacarra, págs. 67-69 (versión española) y 126-127 (texto latino).

42 Poema de Mio Cid, ed. Ramón Menéndez Pidal (Madrid: La Lectura, 1913) págs. 33-37.

43 En Pedro alfonso (Disciplina clericalis, eds. Ducay y Lacarra, pág. 35) se señala la existencia de vínculos entre los exempla de la disciplina y otras obras medievales, como los fueros, lo que pudo contribuir a la difusión de los mismos y a su llegada a otros textos, como el Sendebar y el Poema de Mio Cid:

«No obstante, hay otro aspecto de la difusión menos conocido pero de innegable interés. Me refiero a la interacción entre algunos ejemplos de la Disciplina y algunos cuentos insertados en fueron medievales. En el derecho consuetudina- 
Con Miguel Garci-Gómez ${ }^{44}$ consideramos que el análisis de aspectos concretos como el uso de las arcas puede permitirnos avanzar en el estudio de varios motivos literarios relacionados, y Morros ya había señalado en su estado de la cuestión que la historia del fraude de las arcas tenía un evidente origen árabe ${ }^{45}$.

rio el origen de muchas sentencias jurídicas está claramente vinculado a las anécdotas de donde derivan. Sin embargo, entre la "fazaña" (nombre con el que se conocen estos esbozos narrativos recogidos en los fueros) y la codificación legislativa suele haber un proceso de depuración y elaboración que lleva a extraer de ese episodio narrativo el precepto jurídico abstracto. Pero no siempre se cumple esto y en ocasiones los fueros recogen el caso jurídico novelizado como ejemplo del precepto. En la Disciplina los ejemplos XV (Ejemplo de los diez cofres), XVI (Ejemplo de los toneles de aceite) y XVII (Ejemplo de la serpiente de oro) plantean auténticos problemas jurídicos resueltos sagazmente por una anciana o un filósofo que dictan la sentencia justa. En otros textos literarios, como el Sendebar o el Poema de Mio Cid, hay motivos análogos; en el Cantar épico Minaya actuará como «depositario fiel entregando unas arcas, supuestamente repletas de tesoros, pero en realidad rellenas de arena. ...».

La forma en que se establece este tipo de juego literario, este diálogo entre los textos, no se restringía únicamente a los narradores de cuentos, de la propia Disciplina Clericalis y otros de los propios cantares de gesta. El uso de los exempla por parte de los predicadores cristianos medievales aseguró una difusión mucho más amplia, sobre todo cuando se generalizó su uso a partir del siglo XII, como leemos en la pág. 33:

«Entre las diversas fuentes de inspiración de los predicadores medievales, la obra de Pedro Alfonso fue, sin duda, la favorita. Sólo así nos explicamos los más de sesenta manuscritos repartidos por todas las bibliotecas europeas. Cuando a partir de los siglo XIII la importancia creciente de los ejemplos origine la aparición de compilaciones para uso de predicadores, su nombre y sus cuentos reaparecerán con frecuencia. Los ejemplarios más divulgados, como el de Jacques de Vitry, Etienne de Bourbon o, en España, el Libro de los exemplos por a.b.c., recurrirán a la Disciplina».

44 Miguel Garci-Gómez, «Don Rachel e Vidas, amigos caros. Replanteamiento», Revista de Filología Española 56 (1973) págs. 209-228: 212.

45 Bienvenido Morros, «Problemas del Cantar de Mio Cid: El destierro y el episodio de Raquel y Vidas», en Actas del II Congreso de la Asociación Hispánica de Literatura Medieval, eds. José Manuel Lucía Megía, Paloma García Alonso y Carmen MarTín DAZA (Madrid: Universidad de Alcalá, 1992) págs. 527-548: 534: «Se han querido ver ciertas concordancias entre el relato castellano de Raquel y Vidas y un ejemplo latino recogido en la Disciplina Clericalis de Pedro Alfonso, seguramente ex prouerbiis et castigacionibus arabicis ('de proverbios y consejos árabes')». 
Es necesario señalar que el episodio de las arcas, en una versión muy cercana a la de Akiba, se encuentra en Los Milagros de Nuestra Señora de Gonzalo de Berceo ${ }^{46}$; el carácter compartido de buena parte de la narrativa medieval judía y cristiana ya fue puesto de manifiesto en diferentes ocasiones y de forma convincente en el reciente estudio de Amparo Alba y Carlos Sáinz de la Maza ${ }^{47}$, y Álvaro Galmés de Fuentes ya llamó la atención acerca de la presencia en Las mil y una noches de una narración muy semejante ${ }^{48}$.

Es obvio para todo el que conozca incluso superficialmente la historia crítica de Los Milagros de Nuestra Señora, de Gonzalo de Berceo, que no se trató de una adaptación peninsular de este viejo tema de la literatura hebrea, sino de una traducción de una versión latina que circulaba en diferentes manuscritos, de los que encontramos muestras en Francia y en Alemania ${ }^{49}$. La llegada de un número bastante alto de judíos a Italia y a Alemania, resultante de la emigración de la comunidad judía norteafricana en el siglo XI ${ }^{50}$, produjo la difusión de las colecciones de cuentos y de las tradiciones literarias de los judíos de aquel tiempo, por una vía poco estudiada hasta la fecha, pero la presencia del motivo literario presente en la devolución de los cofres de Akiba en una recopilación de milagros de la Virgen María en latín deja poco espacio a la duda. Como Paul Zumthor afirmó en más de una ocasión, África terminaba en la Edad Media en

46 Dependiendo de la edición, milagro 23 o 24.

47 Amparo Alba Cecilia y Carlos Sáinz de la Maza, «Señas de identidad judías y cristianas en la cuentística medieval: algunos ejemplos hispánicos», Sefarad 72:1 (2012) págs. 145-190.

48 Álvaro GalmÉs De FuenteS, «Un cuento árabe y un milagro de Berceo», Anaquel de Estudios Árabes 14 (2003) págs. 109-117. La narración referida viene a demostrar el carácter de catálogo completo de todo tipo de cuentística que ha adquirido con el paso del tiempo Las mil y una noches.

49 Avelina Carrera de la Red y Fátima Carrera de la Red, Miracula Beate Marie Virginis (Ms. Thott 128 de Copenhage). Una fuente paralela a Los Milagros de Nuestra Señora de Gonzalo de Berceo (Logroño: Instituto de Estudios Riojanos, 2000).

50 Jonathan M. Elukin, Living Together Living Apart: Rethinking Jewish-Christian Relations in the Middle Ages (Princeton: Princeton University Press, 2007). 
el Rhin ${ }^{51}$, y en el caso de la difusión de la literatura árabe de los hebreos de Túnez, su llegada a Alemania es una muestra más de la difusión de una comunidad que alcanzó un gran éxito comercial en su nueva patria. La transmisión de motivos literarios procedentes de la literatura hebrea, reutilizados por estos en la literatura árabe, alcanzó no sólo a las tradiciones de países limítrofes con el mundo árabe, y a géneros literarios cuentísticos, sino a regiones muy alejadas y a géneros como el hagiográfico.

Resulta difícil trazar la ruta exacta de la transmisión de este motivo literario en la Castilla del medioevo, pues además de proceder de la propia cuentística andalusí - poco y mal estudiada, de todas formas, pero en la que resulta evidente el conocimiento de las obras del género alFarây ba'd al-šidda y de otros cercanos como Makārim al-ajlāq- pudo alcanzar el $P M C$ por vía indirecta dentro del mundo cristiano, como acabamos de señalar. Sin embargo, consideramos que el conocimiento del origen judío de cuentos como el del hombre de Gamzu o el de Akiba, era algo sabido en aquel tiempo, y su reelaboración para usarlo en la trama del Poema de Mio Cid tenía buenas razones: que el público que escuchaba la obra conocía, igualmente, los cuentos judíos en que Dios ayudaba a los hebreos a recuperar sus bienes y vencer a los gentiles, $\mathrm{y}$ mediante el robo de los mismos y el ruego posterior a Minaya Alvar Fáñez para que se los devolviera, quedaba claro que Dios no estaba con ellos, sino con el héroe cristiano. Se trata de un caso de intertextualidad en que la subversión de la clave permite al poeta del Cantar demostrar que Dios estaba con los cristianos.

Pensamos que tanto las narraciones de la cuentística árabe, del género al-Faray ba'd al-šidda, como aquellas de origen talmúdico y, evidentemente, la Disciplina Clericalis, eran conocidas y apreciadas en la Castilla de comienzos del siglo XIII, y como veremos a continuación, fueron el referente de este juego literario.

51 Apud Álvaro Galmés De Fuentes, «Un cuento de "Las mil y una noches", el "fabliau Constant du Hamel" y la farsa "Les deulx gentilz hommes et la mounyere"», Revista del Instituto Egipcio de Estudios Islámicos 27 (1995) págs. 41-52. 


\section{El episodio de LaS ARCAS EN EL PMC.}

El ejemplo del episodio de las arcas no es el único caso en el que el $P M C$ puede recibir una explicación, o al menos elementos para construir en el futuro una interpretación más sólida gracias al cotejo de la literatura árabe y hebrea de los siglos X-XII.

Gracias a la obra crítica de los especialistas en Etnografía de la actuación (Performance Ethnography), que han seguido en el estudio de la literatura árabe ${ }^{52}$ la estela de los estudios de Perry y Lord ${ }^{53}$ para la épica de la antigua Yugoslavia, conocemos un poco mejor las variaciones típicas en las representaciones dependiendo de múltiples variables (edad y sexo de la audiencia, diferencias regionales...) por lo que la inclusión de la narración acerca de los judíos no tendría sentido, por ejemplo, ante un auditorio que no contara en sus proximidades con una comunidad judía destacada. Y desde luego ante una comunidad que conociera la respuesta que este texto del PMC suponía a las narraciones en que los judíos recuperaban sus posesiones, robadas por personas de otras religiones, gracias a la ayuda divina. La burla ${ }^{54}$ del Cid del poema a los judíos Rachel y Vidas ${ }^{55}$ no es sólo una forma de conseguir

52 Dwight Reynolds Heroic Poets, Poetic Heroes: The Ethnography of Performance in an Arabic Oral Epic Tradition (Ithaca: Cornell University Press, 1995).

53 Adam Parry, (ed.), The Making of Homeric Verse: The Collected Papers of Milman Parry (New York-Oxford: Oxford University Press, 1987).

${ }^{54}$ Como señala John Rutherford en «The Comical and the Humorous in the Poema de Mio Cid», Bulletin of Spanish Studies 83:6 (2006) págs. 739-769, el episodio de las arcas es uno de los tres de más contenido humorístico del PMC. Vid. Salvatore LuONGO, «Facciata cómica e contenuto serio nell'episodio di Rachel e Vidas del Cantar de Mio Cid», en L'épopée romane. Actes du XVe Congrés International de la Société Rencesvals, eds. Gabriel Bianciotto y Claudio Galderisi (Poitiers: Université de Poitiers-CESCM, 2002), vol. I, págs. 589-599.

55 Aunque Francisco Cantera Burgos («Raquel e Vidas», Boletín de la Institución Fernán González 132 [1955] págs. 631-633) lo descartara en su estudio acerca de los dos judíos de Burgos, y otro tanto Eva Salomonski («Raquel e Vidas» Vox Romanica 17 [1956] págs. 215-230: 222) con argumentos similares. La propuesta de Ángel de los Ríos y Saroihandy acerca de que Vidas pudiera ser Judas, por una mala lectura o una deformación del nombre, tendría sin duda un fuerte elemento cómico, ya que se trataría del traidor traicionado. De hecho, tal y como señaló Colbert I. NePAulsingh («New Light on the 'Raquel and Vidas Episode' in the Poema de Mio Cid?», The American 
una victoria ante una minoría muy asociada al poder real en la Castilla del s. XIII, con lo que en cierta forma el Cid venga su expulsión del reino por Alfonso VI. También es una afirmación de la superioridad de la religión cristiana sobre la judía, pues las intervenciones divinas serán en favor del Cid, no de los judíos, que perderán su dinero de manera definitiva. La entrevista de Alvar Fáñez en los versos 14301438:

$\begin{aligned} & \text { El bueno de Minaya pensar quiere de cavalgar; } \\ & \text { afevos Rachel e Vidas a los pies le caen } \\ & \text { ¡Merced, Minaya, cavallero de prestar! }\end{aligned}$
¡Desfechos nos ha el Cid, sabet, si no nos val!
Soltariemos la ganancia, que nos diesse el cabdal.
$\begin{aligned} & \text { Yo lo veré con el Cid si Dios nos lieva allá, } \\ & \text { por lo que avedes fecho } \quad \text { buen cosiment ý avrá } \\ & \text { Dixo Rachel e Vidas: ¡El Criador lo mande! }\end{aligned}$

Si non, dexaremos Burgos, irlo hemos buscar-

En algún caso se ha afirmado que el Cid sí habría pagado a los judíos ${ }^{56}$, sin embargo consideramos que, como ya señalaron en su día tanto Menéndez Pidal ${ }^{57}$ como María Jesús Lacarra ${ }^{58}$, esta posibilidad desconoce la forma exacta del motivo literario estudiado en estas páginas; ambos planearon también la multiplicidad de vías por las que se difundieron en Europa este tipo de narraciones.

Sephardi 9 [1978] págs. 149-153: 151): «There is a possibility that the numbers 600 and 300 , as multiples of 30, might have been associated in the medieval Christian mind with the alleged treachery of Judas Iscariot». En estas breves páginas hemos dejado de lado de forma intencionada el aspecto de la onomástica de este pasaje del PMC, pues su complejidad lo hace objeto de un estudio posterior.

56 Es interesante consultar para este asunto las breves notas de Seymour RESNICK, «Raquel e Vidas», Hispania 39:3 (1956) págs. 300-304.

57 Poema de Mio Cid, ed. MenÉndez Pidal, págs. 33-37.

58 Pedro Alfonso, Disciplina clericalis, eds. Ducay y Lacarra, pág. 35. 


\section{A MODO DE CONCLUSIÓN}

Afirmamos, con Alfonso Boix ${ }^{59}$, que el engaño del Cid a los judíos Rachel y Vidas fue la primera victoria del $P M C$, y consideramos que además del objetivo material, que es una obsesión a lo largo de toda la obra, hay otro de tipo religioso: reclamar que Dios ha abandonado a los judíos y traspasado su protección a los cristianos, razón por la que Rachel y Vidas no pueden sino esperar en vano la devolución del dinero perdido a manos del Cid.

Las leyendas acerca de arcas de dinero, de oro u otros tesoros, robados a personas pías de religión hebrea, y recuperados gracias al favor divino, eran desde tiempos inmemoriales frecuentes en el folclore judío, y como hemos podido ver fueron incorporadas a las colecciones de cuentos árabes, tanto en Oriente Medio como en Túnez y en al-Andalus, en especial a una variante de Al-Faraŷ ba'd al-šidda y, posteriormente, a otras antologías. Sin duda eran conocidas en al-Andalus y muy posiblemente en Castilla, aunque la forma concreta de ese conocimiento sea más complejo de analizar pues las vías de difusión tanto de la cuentística medieval de Oriente como de las formas literarias árabes en un medio romance son difíciles de trazar con seguridad. Las narraciones que proponemos en este estudio son parte de la corriente que dio origen a una construcción narrativa peculiar en el $P M C$. El Cid consigue el dinero que necesitaba gracias a ese engaño, típico de los cuentos judíos, y que además se encuentra en algunas narraciones andalusíes de carácter épico, incorporadas a las crónicas palaciegas, como la de Ibn Ḥayyān. Este motivo literario tampoco era desconocido en las fuentes literarias medievales romances.

También se respeta la lógica interna de la narración, pues en los versos 164-165 se deja claro que, si los judíos abrían las arcas antes de la fecha convenida, perdían toda la ganancia prometida. Pero como muestra la desesperada súplica a Alvar Fáñez de los dos judíos engaña-

59 Boix Jovaní, «La primera victoria del Cid en el Poema de Mío Cid», págs. 363368. Es necesario señalar que esta afirmación no era en absoluto dada por supuesta; de hecho, Leo Spitzer (Sobre antigua poesía española [Buenos Aires: Universidad de Buenos Aires-Facultad de Filosofía y Letras, 1962] pág. 14) consideraba el episodio de las arcas el punto más bajo de la carrera del Cid, a partir del cual empieza su ascenso. 
dos por el Cid, no reciben compensación alguna. Dios no está con los judíos en este texto literario castellano del siglo XIII, no han recibido grandes riquezas que los compensen por la pérdida de su dinero, no ha salido ningún tesoro a su paso, enviado por Dios, ni han engañado a su burlador para recuperarse, y su aparición en la segunda ocasión en el $P M C$ lo afirma; no aparecen para sugerir un posible pago posterior: aparecen para demostrar que Dios apoya a los cristianos, no a los judíos, y de una manera burlona queda confirmado algo que, en el caso de los musulmanes, es establecido por la suerte de las armas.

Recibido: $14 / 02 / 2019$

Aceptado: 27/08/2019 